\title{
A Study of the Mastery of Complex Sentences of Pre-Service English Teachers
}

\author{
Adaninggar Septi Subekti \\ Duta Wacana Christian University
}

\begin{abstract}
This study reported a research conducted to find out the mastery of complex sentences of students of Writing 5 of an English Education Program in Indonesia. The participants of the research were 24 pre-service English teachers in a Writing 5 class at an English Education program in Indonesia. It used document analysis as the main method of data collection.

The study obtained some important findings. First, complex sentences containing multiple clause structures became the most frequently written of all, and among the four types of complex sentences, ones containing multiple clause structures became the most frequently written of all complex sentences. Secondly, students' mastery of complex sentences containing noun clauses, adjective clauses, and adverb clauses was good. Their mastery of complex sentence containing multiple clause structures, however, was surprisingly very low despite that the students had obtained relatively good results on the three above-mentioned basic types of complex sentence.
\end{abstract}

Keywords: Mastery, complex sentences, noun clauses, adjective clauses, adverb clauses, multiple clause structures

\section{INTRODUCTION}

Learning a language is not easy. It includes learning its four basic skills, namely listening, reading, speaking and writing, and three elements, namely pronunciation, grammar/structure and vocabulary.

Grammar, specifically, is one of the most important elements to learn in order to be fluent in the four basic language skills mentioned previously. Emphasizing the importance of grammar, Radford (1990) stated that "a grammar of a particular language will take the familiar form of a set of rules or principles which tells how to speak and understand the language" (p. 2). In other words, it is about principles specifying how to form, pronounce, and interpret phrases and sentences.

It is also noted that written language and spoken language are different. Written language is usually longer than spoken language (Hyland, 2002; Weigle, 2007) because writing, mostly, conveys ideas in a more organized manner, and as such it needs longer utterances. Hyland (2002) even states that writing is structurally complex and it often includes long clauses and frequent use of subordinators.

\subsection{Rationales}

Some experts believed that grammar is a frame through which meaning is expressed (e.g.: Dulay, Burt, \& Krashen, 1982; Krashen \& Terrell, 1983). Furthermore, they held the opinion that ability in language could be observed through ones' ability to produce complex sentences. It is due to the complexity of each of the sentence, which may include a number of grammatical rules at the same time. Even though it is realized that it is not obligatory to convey an idea through a complex sentence when one can say the same thing through more than one sentence, in writing, a writer is often supposed to convey information directly in a sentence to enhance coherence and to avoid repetitions (Bramer \& Sedley, 1981).

\subsection{Research Questions}

Considering the rationales mentioned above, this study aimed to answer the following research questions: 
1) To what extent do the pre-service teacher students use complex sentences in their Mid Test 1 research reports?

2) How is these participants' mastery of complex sentences as seen in their Mid Test 1 research reports?

\section{LITERATURE REVIEW}

Mastery refers to "great knowledge about or understanding of a particular thing (Hornby, 2005). Related to the structural devices discussed in this paper, one is considered to have mastered these structural devices if he or she:

a. knows the forms and the rules underlying it

b. know the meaning of those forms

c. know how to use construction correctly and appropriately

Besides complex sentences, discussed further in this paper, there are three other types of sentences, namely simple, compound, and compound-complex sentences (Andersen, 2014). A simple sentence consists of a subject and at least one finite verb (Eastwood, 2002). It consists of one independent clause, a clause consisting of the main subject and verb of a sentence (Bram, 1995). Compound sentences, furthermore, are sentences consisting of more than one independent clause (Bram, 1995), joined by coordinating conjunctions, semicolons, or a semicolon followed by a transition (Verde, 2008). Finally, compound-complex sentences refer to sentences with coordinating conjunctions connecting two or more independent clauses, at least one of which should have a dependent clause within (Verde, 2008).

More specifically about complex sentences, a sentence is said to be a complex sentence if it consists of one independent clause and one or more dependent clause (Azar, 1999; Department for Education and Employment, 2000). Bram (1995) stated that independent clause refers to a clause that can stand alone as a complete sentence for it has a subject and a finite verb of a sentence. Azar (1999), furthermore, explained that a dependent clause must be connected to an independent clause. The dependent clauses of complex sentences can be in the forms of noun clauses, adjective clauses and adverb clauses.

Furthermore, implying the importance of complex sentences in writing, Bram (1995) stated that to write grammatically correct sentences is not enough. He claimed that since thinking is sorting out and giving order to ideas, one must find the sentence structure that establishes the proper thought relationship of ideas. It is very important to place the emphasized or prominent idea in the independent clause, and to arrange the less important or deemphasized ideas in suitable subordinate constructions (Department for Education and Employment, 2000). In addition, Bram (1995) also stated, "the flow of thoughts will run much more smoothly, compared with series of ideas expressed in simple sentence" (p. 40). Besides, a previous study on Indonesian students' mastery on complex sentences found that complex sentences became the most frequently written sentences in the participants' essays (see Cahyono, Mukminatien, \& Amrina, 2016).

Furthermore, complex sentences can contain finite and non-finite dependent clauses (Radford, 1990). Radford (1990), furthermore, stated that the distinction between finite and non-finite clauses is partly on morphological criteria, the forms of verbs. A clause is finite if it contains a finite verb, showing tense distinction between 'past' and 'present', and being associated with a particular subject. In comparison, a clause is said to be non-finite, if it lacks a finite verb (Radford, 1990). Non-finite clauses remain constant in form whatever the context and they cannot carry finite Tense/Agreement inflections such as present or past tense (Eastwood, 2002).

Eastwood (2002) then stated that there are three types of non-finite verb forms in English.

a. Infinitive forms (infinitive particle)

It includes simply the base or stem of the verb with no added inflection.

Example: The man did not know where to find the ring.

b. Gerund forms

It includes the base plus the -ing suffix.

Example: Speaking in a language, people often insert some words from another language within sentences.

c. Participle forms(perfect/passive)

It includes the $\mathrm{V}_{3}$ or past participle used both in passive or perfect.

Example: This paper reports a research conducted to know the code switching habit of students of semester six.

More specific about dependent clauses of complex sentences, Quirk \& Greenbaum (1985) divided them into three broad categories, namely noun clause, adjective clause, and adverb clause. 


\subsection{Noun Clauses}

Noun clauses are dependent clauses replacing a noun or noun phrase (Eastwood; 2002). The same as a noun, used as a subject or an object, a noun clause is used as a subject or an object (Azar, 1999). Therefore, basically, noun clause functions as a noun substitute in a sentence.

Examples:

i. I think that he is a good actor.

ii. I think he is a good actor.

iii. We know (that) the world is round

iv. We know who wrote the letter.

v. We know what happened.

vi. We know whom you saw.

Noun clauses introduced by question words, furthermore, stated, can be changed into non-finite by substituting the clause following the question word with an infinitive (Quirk \& Greenbaum, 1985).

1) I do not know what I should do. $\rightarrow$ I do not know what to do.

2) Pam cannot decide whether she should go or stay home. $\rightarrow$ Pam cannot decide whether to go or (to) stay home.

\subsection{Adjective Clauses}

An adjective clause, or called a relative clause, Azar (1999) stated, is a dependent clause that modifies or tell more about a noun. It describes, identifies, or gives further information about a noun. It means that an adjective clause is used as an adjective. Furthermore, adjective clauses are usually introduced by the relative pronoun (Lynch \& Anderson, 2013). These pronouns function in noun positions in the clauses they introduce.

In writing, adjective clauses play an important role to improve coherence (Bramer \& Sedley, 1981) as they can help avoid repetitions by substituting a pronoun for a noun or noun phrase that has been mentioned previously. Therefore, it can help make ideas within a composition flow smoother.

Examples:

I thanked the woman. She helped me

$$
\downarrow
$$

i. I thanked e woman who helped me.

ii. I thanked the woman that helped me.

The book is mine. It is on the table.

$$
\downarrow
$$

iii. The book which is on the table is mine.

iv. The book that is on the table is mine

The movie was not very good.

We saw it last night.

$\downarrow$

v. The movie which we saw last night was not very good.

vi. The movie that we saw last night was not very good.

vii. The movie $\theta$ we saw last night was not very good. viii. I know the man whose bicycle was stolen.

Mr. Catt has a painting. Its value is inestimable.

ix. Mr Catt has a painting whose value is inestimable.

Tom was late. That surprised me.

x. Tom was late, which surprised me.

I know the man.

His bicycle was stolen. 
Furthermore, Azar (1999) stated there are two ways in which a finite adjective clause is changed to a non-finite adjective clause, or adjective phrase.

1) The subject pronoun is omitted and the "be" form of the verb is omitted.
CLAUSE
: The man who is talking to John is from Korea.
PHRASE
: The man $\theta \theta$ talking to John is from Korea.

2) If there is no be form of the verb in the adjective clause, it is sometimes possible to omit the subject pronoun and change the verb to its -ing form.
CLAUSE
: Anyone who wants
: Anyone $\theta$ wanting
to come with us is welcome.
PHRASE
to come with us is welcome.

\subsection{Adverb Clauses}

Dumais (1988) stated that an adverbial clause is a dependent clause used as an adverb. It, basically, modifies or tells more about a verb (Farbman, 1985), in the way that they explain where, when, how, why, to what extent and under what condition an action occurs. As an adverb does not have a fixed position, adverb clauses, consequently, do not occupy any fixed position.

Examples:

i. $\quad$ After she graduates, she will get a job. (Indicating time relationships)

ii. Because he was sleepy, he went to bed. (Indicating cause and effect relationships)

iii. Although I had a slight handicap, I was an ambitious student. (Indicating oppositions)

To change finite adverb clauses into non-finite, the subject of both the independent and the dependent clause in the sentence to be changed into non-finite must be the same (Wishon \& Burks, 1987). Their ideas can be summed up in the examples below.

1) While I was walking down the street, I met an old friend. $\rightarrow$ Walking down the street, I met an old friend.

2) Because she needed money to buy a book, Sue cashed a check. $\rightarrow$ Needing some money to buy a book, Sue cashed a check.

3) Although I had a slight handicap, I was an ambitious student. $\rightarrow$ Although having a slight handicap, I was an ambitious student.

\subsection{Multiple clause structure}

The device of subordination, according to Quirk \& Greenbaum (1985), enables one to organize multiple clause structure. In this structure, each dependent clause may itself be superordinate to one or more other clauses. As the consequence, hierarchy of clauses, one within another can be built up, which frequently results in sentences of great complexity.

A simple example:

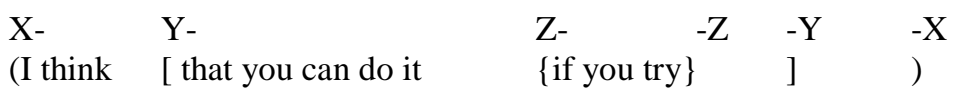

Here, the clause beginning at Z- is subordinate to the clause beginning at $\mathrm{Y}$-, which in turn is subordinate to the clause beginning at $\mathrm{X}$-. Both $\mathrm{Y}$ and $\mathrm{Z}$ are dependent clause, while $\mathrm{X}$ is the independent clause of the sentence above. And the sentence fulfils the pattern of S-V-O-A, in which $\mathbf{I}$ functions as $\mathrm{S}$, think as $\mathrm{V}$, that you can do it as $\mathrm{O}$, and if you try as $\mathrm{A}$.

\subsection{Summary of the chapter}

Sentences are divided into four broad categories namely simple, compound, complex, and compound-complex. Complex sentences becoming the focus of this study are those having one independent clause, and at least one dependent clause, which can be in the form of finite or non-finite noun clause, adjective clause, adverb clause, and multiples clause structures.

Complex sentences that will be analyzed in this study, therefore, can be noted as follows.

1) Complex sentences containing finite or non-finite noun clauses

2) Complex sentences containing finite or non-finite adjective clauses 
3) Complex sentences containing finite or non-finite adverb clauses

4) Complex sentences containing multiple clause structure

\section{RESEARCH METHOD}

\section{a. Rationales for the method used}

A previous research on complex sentences was conducted by Cahyono et al. (2016) to investigate the correlation between the participants' total number of complex sentences and the writing scores. However, the mastery of complex sentences in writing was not investigated yet. Hence, the current study aimed to investigate their complex sentence mastery in a real writing condition.

Different from Cahyono et al.'s (2016) study which used correlation tests, the study used document analysis in which it focused on analysing and interpreting materials within its own context (Ary, Jacobs, \& Razavieh, 2002). This method was chosen because it was considered authentic and natural (Ary et al., 2002) in the way that the participants were to write research reports for their Mid Test 1 as usual. As such, the participants really showed their ability in writing as they usually did. Conducting tests, as many studies of structural devices have conducted, was not chosen based on my informal observations as a teacher and a researcher in which generally students tended to do the tests just to help researchers obtain their data. As such, the results of such tests might not show their real ability and as such, the data obtained might have poor validity (Gray, 2014). Therefore, using document analysis was considered more feasible to maintain the data's validity.

\section{b. The instrumentations and the participants}

Pre-service teacher students of Writing 5, who were in their $6^{\text {th }}$ semester, were chosen based on the consideration that they have obtained upper/advanced Structure classes and as such they were expected to show adequate level of grammar mastery. As teacher candidates, furthermore, they are supposed to have a good command in the language they will be teaching.

Furthermore, the participants' Mid Test 1 research reports became the major source of data. To analyse the documents, some tables of classification operated in Microsoft Excel 2013 were used.

The first table dealt with the total number of complex sentences each student wrote. In more detailed, the table showed the number of sentences students wrote according to sentence types, namely simple, compound, complex, and compound complex.

The second table dealt with the number of students' complex sentences according to the types of the dependent clauses, noun clauses, named type one, adjective clauses, named type two, and adverb clauses, named type three, and multiple clause structures, named type four.

The third tables, furthermore, were summary tables to show the students' mastery of complex sentences. The tables showed the number and the percentage of correct complex sentences type one, type two, type three, and type four. From the percentages, then, the students' mastery of complex sentences could, then, be described, in which the following criteria were given: if a student's total grammatical sentences were $80 \%$ or more, it can be said that his mastery of complex sentences was "very good". If they were lower than $80 \%$ but $70 \%$ at the least, the mastery was considered "good". Lower than "good", grade "fair" was given for those having $60 \%$ grammaticality at the least. When there was less than $60 \%$ grammaticality, the mastery was considered insufficient or "poor".

In short, with the above-mentioned tables of classification, after the total number of sentences written by each student was obtained, those sentences were classified into non-complex sentences, including simple, compound sentences, compound-complex sentences and complex sentences. From the obtained number of complex sentences, students' mastery based on percentage of numbers of grammaticality was investigated based on rules previously stated in Literature Review.

However, even though all of the classification tables explained above helped obtain the study's end results, due to space reason, only tables directly show the results in relation with the research question would be presented. Some tables would be presented in full, while the others would be in shorter (cut) version without reducing relevant information.

\section{c. Access and ethical considerations}

In order to obtain the participants' research reports, this study used the consent of the gatekeeper, who was the teacher of Writing 5 class. In other words, the participants did not know beforehand that their writing would be analysed. When the teacher later told them that their writing would be analysed, 
they did not object. Despite that, it was realised that gatekeeper's consent in the initial data collection might slightly neglect some ethical considerations in research (Goode, 1996). It was unknown whether they would willingly participate if they had been given the choice in the first place. However, there are some considerations in which participants are allowed not to know beforehand that they are being investigated (Israel \& Hay, 2006). One of them is in the case where there is possibility that they will change behaviours to show better performances (Basit, 2010). In addition, if some benefits could be gained through the study in the form of new knowledge, and no harm befalls participants, Goode (1996) argued that such practices in researches are allowed. As previously explained, the use of document analysis was to see the participants' real ability in writing context. As such, not letting the participants know their writing would be analysed might be seen as an effort to keep the validity of data.

Related to the principles of confidentiality not to reveal the identity of research participants (Sarantakos, 1998), numbers \#1 until \#24 were used to conceal the names of the students. For the same reason, the exact name of the university at which the study was conducted was not disclosed either.

\section{RESULTS AND ANALYSIS}

Research Question 1: To what extent do the pre-service teacher students use complex sentences in their Mid Test 1 research reports?

In the following table, the numbers of students' sentences in each of their type were shown.

Table 4.1 The number of simple, compound, and complex sentences

\begin{tabular}{|c|c|c|c|c|c|c|c|c|c|}
\hline \multirow{3}{*}{ No } & \multicolumn{8}{|c|}{ Sentences } & \multirow{3}{*}{$\begin{array}{c}\text { Total } \\
\text { Sentences }\end{array}$} \\
\hline & \multicolumn{2}{|c|}{ Simple } & \multicolumn{2}{|c|}{ Compound } & \multicolumn{2}{|c|}{ Complex } & \multicolumn{2}{|c|}{ Compound-Complex } & \\
\hline & Num & $\%$ & Num & $\%$ & Num & $\%$ & Num & $\%$ & \\
\hline 1 & 29 & $39.7 \%$ & 7 & $9.6 \%$ & 35 & $47.9 \%$ & 2 & $2.7 \%$ & 73 \\
\hline 2 & 103 & $54.5 \%$ & 13 & $6.9 \%$ & 70 & $37.0 \%$ & 3 & $1.6 \%$ & 189 \\
\hline 3 & 25 & $31.3 \%$ & 2 & $2.5 \%$ & 51 & $63.8 \%$ & 2 & $2.5 \%$ & 80 \\
\hline 4 & 41 & $31.8 \%$ & 9 & $7.0 \%$ & 72 & $55.8 \%$ & 7 & $5.4 \%$ & 129 \\
\hline 5 & 65 & $44.5 \%$ & 10 & $6.8 \%$ & 62 & $42.5 \%$ & 9 & $6.2 \%$ & 146 \\
\hline 6 & 25 & $36.2 \%$ & 4 & $5.8 \%$ & 39 & $56.5 \%$ & 1 & $1.4 \%$ & 69 \\
\hline 7 & 29 & $26.9 \%$ & 9 & $8.3 \%$ & 68 & $63.0 \%$ & 2 & $1.9 \%$ & 108 \\
\hline 8 & 31 & $29.2 \%$ & 9 & $8.5 \%$ & 61 & $57.5 \%$ & 5 & $4.7 \%$ & 106 \\
\hline 9 & 27 & $26.5 \%$ & 4 & $3.9 \%$ & 70 & $68.6 \%$ & 1 & $1.0 \%$ & 102 \\
\hline 10 & 32 & $39.5 \%$ & 7 & $8.6 \%$ & 41 & $50.6 \%$ & 1 & $1.2 \%$ & 81 \\
\hline 11 & 56 & $50.9 \%$ & 9 & $8.2 \%$ & 44 & $40.0 \%$ & 1 & $0.9 \%$ & 110 \\
\hline 12 & 24 & $33.3 \%$ & 3 & $4.2 \%$ & 43 & $59.7 \%$ & 2 & $2.8 \%$ & 72 \\
\hline 13 & 39 & $39.0 \%$ & 5 & $5.0 \%$ & 49 & $49.0 \%$ & 7 & $7.0 \%$ & 100 \\
\hline 14 & 83 & $59.3 \%$ & 5 & $3.6 \%$ & 50 & $35.7 \%$ & 2 & $1.4 \%$ & 140 \\
\hline 15 & 30 & $32.3 \%$ & 5 & $5.4 \%$ & 58 & $62.4 \%$ & 0 & $0.0 \%$ & 93 \\
\hline 16 & 49 & $48.0 \%$ & 5 & $4.9 \%$ & 44 & $43.1 \%$ & 4 & $3.9 \%$ & 102 \\
\hline 17 & 23 & $29.5 \%$ & 2 & $2.6 \%$ & 52 & $66.7 \%$ & 1 & $1.3 \%$ & 78 \\
\hline 18 & 44 & $48.4 \%$ & 4 & $4.4 \%$ & 41 & $45.1 \%$ & 2 & $2.2 \%$ & 91 \\
\hline 19 & 58 & $51.3 \%$ & 10 & $8.8 \%$ & 42 & $37.2 \%$ & 3 & $2.7 \%$ & 113 \\
\hline 20 & 42 & $41.2 \%$ & 6 & $5.9 \%$ & 51 & $50.0 \%$ & 3 & $2.9 \%$ & 102 \\
\hline
\end{tabular}




\begin{tabular}{|c|c|c|c|c|c|c|c|c|c|}
\hline 21 & 86 & $56.6 \%$ & 2 & $1.3 \%$ & 62 & $40.8 \%$ & 2 & $1.3 \%$ & 152 \\
\hline 22 & 43 & $46.7 \%$ & 2 & $2.2 \%$ & 47 & $51.1 \%$ & 0 & $0.0 \%$ & 92 \\
\hline 23 & 57 & $58.8 \%$ & 1 & $1.0 \%$ & 36 & $37.1 \%$ & 3 & $3.1 \%$ & 97 \\
\hline 24 & 74 & $57.8 \%$ & 2 & $1.6 \%$ & 51 & $39.8 \%$ & 1 & $0.8 \%$ & 128 \\
\hline Max & $\mathbf{1 0 3}$ & $\mathbf{5 9 . 3 \%}$ & $\mathbf{1 3}$ & $\mathbf{9 . 6 \%}$ & $\mathbf{7 2}$ & $\mathbf{6 8 . 6 \%}$ & $\mathbf{9}$ & $\mathbf{7 . 0 \%}$ & $\mathbf{1 8 9}$ \\
\hline Min & $\mathbf{2 3}$ & $\mathbf{2 6 . 5 \%}$ & $\mathbf{1}$ & $\mathbf{1 . 0 \%}$ & $\mathbf{3 5}$ & $\mathbf{3 5 . 7 \%}$ & $\mathbf{0}$ & $\mathbf{0 . 0 \%}$ & $\mathbf{6 9}$ \\
\hline
\end{tabular}

\begin{tabular}{|l|c|c|}
\hline Simple Sentences & 1115 & $43.7 \%$ \\
\hline Compound Sentences & 135 & $5.3 \%$ \\
\hline Complex Sentences & $\mathbf{1 2 3 9}$ & $\mathbf{4 8 . 5 \%}$ \\
\hline Compound Complex Sentences & 64 & $2.5 \%$ \\
\hline TOTAL SENTENCES & 2553 & $100.0 \%$ \\
\hline
\end{tabular}

From the table above, it could be seen that complex sentences became the most frequent sentences of all for fourteen of 24 participants. Being written 1239 times in students' reports, or approximately $48.5 \%$ of all sentences written, complex sentences occupied the first position as the most frequently written type of sentence of all. Simple sentences, compound sentences, and compound-complex sentences occupied the next positions, respectively.

These results corresponded to Bram's (1995) statement saying that in writing complex sentence uses are inevitable. This is because in writing, very often, writers need to convey complex ideas while at the same time they still need to keep their writing coherent by expressing complex ideas in one complex sentence (Bram, 1995). The results showing that complex sentences were the most frequently written type of sentence might also indicate and reaffirm the importance of the mastery of complex sentences in writing. This result was also in line with the results of Cahyono et al.'s (2016) study in which they also found that complex sentences became the most frequently written sentences in the participants' essays as well.

More specifically, in the following summary table, the classification of the complex sentences into each of their type, namely those containing a noun clause, an adjective clause, an adverb clause, and multiple clause structure can be observed.

Table 4.2 Summary of the number of sentences in each type of complex sentence

\begin{tabular}{|l|c|c|}
\hline Type of Complex Sentences & Number & Percentage \\
\hline Noun Clauses & 317 & $25.6 \%$ \\
\hline Adjective Clauses & 287 & $23.2 \%$ \\
\hline Adverb Clauses & 251 & $20.3 \%$ \\
\hline Multiple Clause Structures & 384 & $31.0 \%$ \\
\hline Complex Sentences & $\mathbf{1 2 3 9}$ & $\mathbf{1 0 0 . 0 \%}$ \\
\hline
\end{tabular}

From the table above, it could be observed that complex sentence type four, containing multiple clause structures with 384 times of occurrences; became the most frequently written sentences. Those containing a noun clause (type one), an adjective clause (type two), and an adverb clause (type three) came right after respectively.

That complex sentences type four led in number compared to the other three types indicated that the students preferred to write sentences containing more than one dependent clause of the same and of different types of dependent clause. It supported Bram's (1995) idea saying that since thinking is sorting out and giving order to ideas, one should find the sentence structure that establishes the proper thought relationship of 
ideas. And as the nature of Writing 5 research report itself which required a great deal of scientific language, complex sentence construction, the results showing multiple clause structure as the most frequently written was not really surprising.

Research Question 2: How is these participants' mastery of complex sentences as seen in their Mid Test 1 research reports?

\section{Complex Sentences type one}

Based on the analysis of complex sentences type one (containing noun clauses) on all of the 24 participants' reports using criteria of mastery scoring presented previously, the following summary was obtained.

Table 4.3 Summary of the participants' mastery on complex sentence type one

\begin{tabular}{|c|c|c|c|c|}
\hline \multirow{2}{*}{$\begin{array}{c}\text { Total Number of Noun } \\
\text { Clauses }\end{array}$} & \multicolumn{2}{|c|}{ Correct } & \multicolumn{2}{c|}{ Incorrect } \\
\cline { 2 - 5 } & Number & $\%$ & Number & $\%$ \\
\hline 317 & 247 & $77.9 \%$ & 70 & $22.1 \%$ \\
\hline
\end{tabular}

\begin{tabular}{|l|c|c|}
\hline \multicolumn{1}{|c|}{ Predicates } & Number of Students & Percentage \\
\hline VERY GOOD & 11 & $45.83 \%$ \\
\hline GOOD & 5 & $20.83 \%$ \\
\hline FAIR & 4 & $16.67 \%$ \\
\hline POOR & 4 & $16.67 \%$ \\
\hline Total & $\mathbf{2 4}$ & $\mathbf{1 0 0 . 0 0 \%}$ \\
\hline
\end{tabular}

As seen from the table above, there were 247 grammatical complex sentences type one. It was nearly $80 \%$ of all written sentences in this type. More specifically, this study also found out that sixteen of 24 participants, or more than half of all the participants, obtained "very good," and "good." Hence, it could be stated that participants' mastery on complex sentence type one was relatively good.

\section{Complex Sentences type two}

The overall findings about students' mastery of complex sentences type two could be observed in the following table.

Table 4.4 Summary of the participants' mastery on complex sentence type two

\begin{tabular}{|l|c|c|c|c|}
\hline \multirow{2}{*}{$\begin{array}{l}\text { Total Number of } \\
\text { Adjective Clauses }\end{array}$} & \multicolumn{2}{c|}{ Correct } & \multicolumn{2}{c|}{ Incorrect } \\
\cline { 2 - 5 } & Number & $\mathbf{2 2}$ & Number & $\%$ \\
\hline \multicolumn{1}{|c|}{$\mathbf{2 8 7}$} & $\mathbf{2 2 2}$ & $\mathbf{7 7 . 4 \%}$ & $\mathbf{6 5}$ & $\mathbf{2 2 . 6 \%}$ \\
\hline Predicates & Number of students & Percentage \\
\hline VERY GOOD & \multicolumn{2}{|c|}{13} & $54.17 \%$ \\
\hline GOOD & \multicolumn{2}{|c|}{4} & $16.67 \%$ \\
\hline FAIR & \multicolumn{2}{|c|}{3} & $12.50 \%$ \\
\hline POOR & 4 & $\mathbf{1 0 0 \%}$ \\
\hline Total & $\mathbf{2 4}$ & \multicolumn{2}{c|}{} \\
\hline
\end{tabular}


The table above showed that students' mastery on complex sentences type two could be considered good for averagely, $77.4 \%$ of all the written sentences were grammatical. The number of those obtaining "very good", and "good" was 17, more than half of the total number of the participants. Thus, the participants' mastery on complex sentences type two in average could be considered good.

\section{Complex Sentences type three}

The overall findings on the participants' mastery of complex sentences type three could be observed in the following table.

Table 4.5 Summary of the participants' mastery on complex sentence type three

\begin{tabular}{|c|c|c|c|c|}
\hline \multirow{2}{*}{$\begin{array}{c}\text { Total Number of Adverb } \\
\text { Clauses }\end{array}$} & \multicolumn{2}{|c|}{ Correct } & \multicolumn{2}{c|}{ Incorrect } \\
\cline { 2 - 5 } & Number & $\%$ & Number & $\%$ \\
\hline 251 & 192 & $76.5 \%$ & 59 & $23.5 \%$ \\
\hline
\end{tabular}

\begin{tabular}{|l|c|c|}
\hline \multicolumn{1}{|c|}{ Predicates } & Number of students & Percentage \\
\hline VERY GOOD & 12 & $50.00 \%$ \\
\hline GOOD & 3 & $12.50 \%$ \\
\hline FAIR & 7 & $29.17 \%$ \\
\hline POOR & 2 & $8.33 \%$ \\
\hline Total & $\mathbf{2 4}$ & $\mathbf{1 0 0 \%}$ \\
\hline
\end{tabular}

As seen from the table above, 192 complex sentences type three of 251 were grammatical. The number was $76.5 \%$ of all sentences written. Even though at glance, this percentage is lower than that of the previous types of complex sentences, only two students of twenty-four obtained "poor". Exactly half of the students obtained "very good" while three students obtained "good". Then, the number of students who obtained "fair," which was only seven, became a considerable numbers of minorities. Overall, however, students' mastery on this type of complex sentence was good enough.

\section{Complex Sentences type four}

Furthermore, the participants' mastery on complex sentences type four, containing multiple clause structures could be seen in the table below.

Table 4.6 Summary of the participants' mastery on complex sentence type four

\begin{tabular}{|c|c|c|c|c|}
\hline \multirow{2}{*}{$\begin{array}{c}\text { Total Number of Multiple Clause } \\
\text { Structures }\end{array}$} & \multicolumn{2}{|c|}{ Correct } & \multicolumn{2}{c|}{ Incorrect } \\
\cline { 2 - 5 } & Number & $\%$ & Number & $\%$ \\
\hline 384 & 218 & $56.8 \%$ & 166 & $43.2 \%$ \\
\hline
\end{tabular}

\begin{tabular}{|l|c|c|}
\hline Predicates & Number of students & Percentage \\
\hline VERY GOOD & 3 & $12.50 \%$ \\
\hline GOOD & 4 & $16.67 \%$ \\
\hline FAIR & 6 & $25.00 \%$ \\
\hline POOR & 11 & $45.83 \%$ \\
\hline Total & $\mathbf{2 4}$ & $\mathbf{1 0 0 \%}$ \\
\hline
\end{tabular}


From the table, it could be seen that students' mastery of complex sentence type four was much different from those of the other three types of complex sentences. Overall, only 218 sentences of 384 were grammatical, with the other 166 sentences being ungrammatical. The ungrammaticality was found in $43.2 \%$ of the total sentences. In other words, generally, the participants' overall mastery of complex sentence in this type could be considered low, despite that their mastery on the other basic types of complex sentences was quite good.

This was strengthened by the results showing the percentage of students obtaining "very good" that drastically went down into $12.50 \%$, representing merely three students of 24 . On the other hand, the number of those obtaining "poor" increased up to more than $45 \%$, representing eleven students of 24 . That one fourth of all participants obtained "fair" and one sixth of all participants obtained "good" could not hide that students' mastery on this type of complex sentences was relatively low, averagely. below.

The overall results of the participants' mastery on complex sentences could be observed in the table

Table 4.7 Summary of the overall numbers of grammaticality

\begin{tabular}{|l|c|c|c|c|c|}
\hline \multirow{2}{*}{\multicolumn{1}{c|}{ Complex Sentences }} & \multirow{2}{*}{ TOTAL } & \multicolumn{2}{c|}{ Correct } & \multicolumn{2}{c|}{ Incorrect } \\
\cline { 3 - 6 } & & Number & $\%$ & Number & $\%$ \\
\hline Noun Clauses & 317 & 247 & $77.9 \%$ & 70 & $22.1 \%$ \\
\hline Adjective Clauses & 287 & 222 & $77.4 \%$ & 65 & $22.6 \%$ \\
\hline Adverb Clauses & 251 & 192 & $76.5 \%$ & 59 & $23.5 \%$ \\
\hline Multiple Clause Structures & 384 & 218 & $56.8 \%$ & 166 & $43.2 \%$ \\
\hline TOTAL & 1239 & 879 & $70.9 \%$ & 360 & $29.1 \%$ \\
\hline
\end{tabular}

From the table above, some results could be commented. Firstly, even though the total grammaticality nearly reached $71 \%$, this came mostly from the first three types of complex sentences only. It was because students' mastery went down drastically in the fourth type of complex sentence. Interestingly, the last type of complex sentences in which the participants mostly produced ungrammaticalities, were the type of complex sentences they wrote most frequently (see research question 1). This result, furthermore, might suggest that the solitary applications of the three basic categories of complex sentences (containing noun clauses, adjective clauses, and adverb clauses) might not meet learners' need in real writing situations. As the result suggested, complex sentences containing multiple clause structures became the most frequently written sentences on which the participants' errors were mostly located. As the consequence, the students' mastery of multiple clause structures might be more needed in their real writing conditions.

This might be rooted to the participants' upper/advanced Structure classes, which was mostly taught in isolation. Students, despite being taught various tenses, and grammatical points, were accustomed to studying structural devices of English in isolated sentences without any larger contexts. As such, when they were in real writing situations where they were required to convey complex ideas, they might lose their knowledge of complex sentences obtained in Structure classes. That their mastery on multiple clause structures was low despite their relatively good mastery in the three basic types of complex sentences might support this.

\section{CONCLUSIONS}

\subsection{Summary}

From the results of this study, some important points can be summarised. First, it was found that among four types of sentences, complex sentences were the most written sentences in students' research reports. Complex sentences type four, containing multiple clause structures, became the most frequently written complex sentences compared to the three basic types of complex sentences.

Students' mastery on complex sentences type one, type two, and type three could be considered sufficient. It could be seen from the range of the overall mastery, from 70 up to 80 . Even though some 
students still obtained lower results than the average, they were considered minority compared to those obtaining better results.

Students' mastery on complex sentences type four, containing multiple clause structures, in comparison, could be considered insufficient in which half of the participants obtained poor results. Many of the students obtaining good results in the three basic types obtained poor result in this type of sentences.

\subsection{Implications}

First, the results might inform Structure Class teachers. The poor results of the students' mastery on complex sentence type four might suggest that Structure Class teachers should pay attention to multiple clause structures more than three basic types of complex sentences. They are to provide students more opportunities to train their ability in writing this last type of complex sentences. Teachers can promote more sentence production exercises, for example. Here, students are to produce sentences having various combinations of dependent clauses.

Furthermore, teaching grammar and structure contextually may also be a better choice than teaching them in isolation. Rather than providing exercises from outside, teachers can provide exercises in the form of sentences the students themselves write. The activities can be in the form of analysing the errors in small group discussions. In so doing, besides being able to provide contextual learning, teachers can carry out error corrections in non-threatening way. Writing a paragraph can also be conducted in Structure class to train students' mastery of English structure in real writing conditions.

Furthermore, the results could also inform the students, especially pre-service teacher students of latter semesters. As many may choose path to be future educators, they should be more responsible for their own learning. Students could, for example, have peer revisions outside the class independently because writing is a matter of practice, including practising in using grammatically correct sentences in essays.

\subsection{Limitations}

Despite the results and the above-mentioned implications, it was acknowledged that this study had some limitations. First, the interpretation of grammaticality and ungrammaticality was based on theories of grammar and syntax. Thus, the results should be viewed according to the framework the study used. Secondly, it might be arguable to state that the results could be generalised in wider contexts. However, the study could pave a way to understand the role of syntactic structures in writing better.

\subsection{Future Studies}

In the light of the implications and limitations of the study, the following suggestions for future studies are presented. The first is to conduct a classroom action research investigating the use of contextual Structure learning on students' mastery on certain grammatical points in writing. Secondly, it is fully realized that grammar is not the only parameter of writing quality. In the document analysis process, it was found that some students wrote good essays in poor English while some others wrote relatively poor essay in good English. Therefore, it is suggested that future studies attempt to seek the relationship between grammatical accuracy and the overall writing quality.

\section{REFERENCES}

Andersen, S. (2014). Sentence Types and Functions. Retrieved from San José State University Writing Center : www.sjsu.edu/writingcenter

Ary, D., Jacobs, L., \& Razavieh, A. (2002). Introduction to Research in Education (Sixth Edition) . Belmonth, CA: Wadsworth/Thomson Learning.

Azar, B. (1999). Understanding and Using English Grammar. New York: Pearson Education. 
Basit, T. N. (2010). Conducting Research in Educational Contexts. London: Continuum International Publishing Group.

Bram, B. (1995). Write Well: Improving Writing Skill. Yogyakarta: Kanisius.

Bramer, G., \& Sedley, D. (1981). Writing for Readers. Colombus, Ohio: Charles E. Merrill Publishing Co.

Cahyono, B., Mukminatien, N., \& Amrina, R. (2016). Indonesian Students' Writing Proficiency and Their Ability in Using Complex Sentences. International Journal on Studies in English Language and Literature (IJSELL), 4(9), 22-32.

Department for Education and Employment (2000). The National Literacy Strategy: Grammar for Writing. London: Department for Education and Employment.

Dulay, H., Burt, M., \& Krashen, S. (1982). Language Two. Oxford: Oxford University Press.

Dumais, L. (1988). Writing in English. Jakarta: Departemen Pendidikan dan Kebudayaan.

Eastwood, J. (2002). Oxford Guide to English Grammar. Oxford: Oxford University Press.

Farbman, E. (1985). Signals: A Grammar and Guide for Writer. Boston: Houghton Mifflin Company.

Goode, E. (1996). The ethics of deceptions in social researches: A case study. Qualitative Sociology, 19(1), 11-33.

Gray, D. (2014). Doing Research in the Real World (Third Edition). London: Sage Publications, Ltd.

Hornby, A. (2005). Oxford Advanced Learner's Dictionary (Seventh Edition). Oxford: Oxford University Press.

Hyland, K. (2002). Teaching and Researching Writing. London: Pearson Education.

Israel, M., \& Hay, I. (2006). Research Ethics for Social Scientists. London: Sage Publications.

Krashen, S., \& Terell, T. (1983). The Natural Approach: Language Acquisition in the Classroom. Oxford: Pergamon Press.

Lynch, T., \& Anderson, K. (2013). Grammar for Academic Writing. Edinburgh: English Language Teaching Center, the University of Edinburgh.

Quirk, R., \& Greenbaum, S. (1985). A University Grammar of English. Harlow, Essex: Longman Group Limited.

Radford, A. (1990). Transformational Grammar. Cambridge: Cambridge University Press.

Sarantakos, S. (1998). Social Research (Second Edition). London: Macmillan Press Ltd.

Verde, V. (2008, 01 15). Kinds of Sentences and Patterns. Retrieved from www20.csueastbay.edu: http://www20.csueastbay.edu/library/scaa/files/pdf/kindsofsentencesandpatterns.pdf

Weigle, S. C. (2007). Assessing Writing. Cambridge: Cambridge University Press.

Wishon, G., \& Burks, J. (1987). Let's Write English (Revised Edition). New York: Litton Educational Publishing, Inc. 